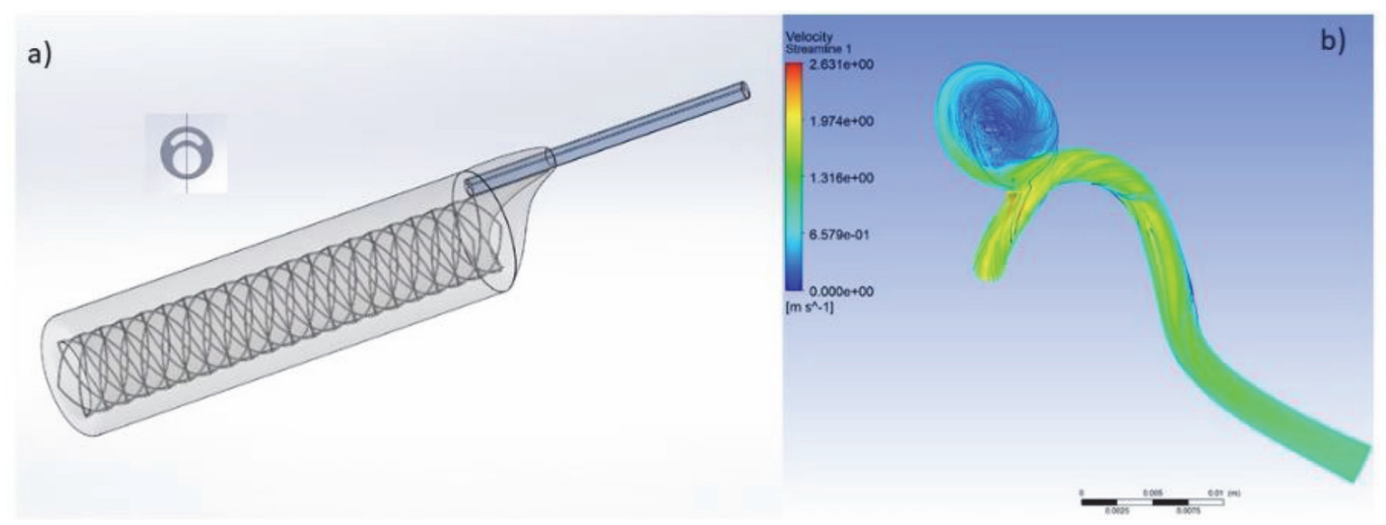

Abstract 0-006 Figure 1 a) CAD rendering of the balloon stent microcatheter device and cross-sectional view (upper right); b) results of a Computational Fluid Dynamic (CFD) simulation rendering velocity streamlines of an ICA aneurysm

derived from Fractional Flow Reserve without induced hyperemia. An FPR, with $\mathrm{a} \% \Delta \mathrm{P}<25 \%$ (equivalent to $>0.75$ FPR), is a strong indicator of patent artery flow. FPR during balloon-stent deployment was simulated using Computational Fluid Dynamics (figure 1b) and validated using benchtop modeling in a circle of Willis (CW) vessel phantom equipped with real-time branch pressure and flow monitoring.

Results A balloon-stent with a stent ID > 56\% of parent artery ID maintained $\% \Delta \mathrm{P}<25 \%$ during deployment and will minimize ischemic risk. A balloon-stent device can temporarily provide aneurysm neck protection during complementary device deployment while maintaining blood flow in the parent artery. A $2.6 \mathrm{~F}$ Penumbra Velocity ${ }^{\circledR}$, jailed next to a balloonstent device permitted an inflation ID $>56 \%$ of parent artery ID, will maintain $\% \Delta \mathrm{P}<25 \%$ during deployment and will minimize ischemic risk. The prototype maintained safe FPR and parent vessel during in vitro and CFD simulations.

Conclusion A balloon-stent device can provide neuro-interventional surgeons with a larger time-frame to deploy embolic without blood flow arrest and the need for repeated balloon inflation/deflations. In addition, this novel medical device has the potential to provide a smooth surface at the aneurysm neck for consistent device placement, minimize parent vessel trauma, eliminate ischemic effects distal to the parent artery, and minimize intra-saccular flow remnants pre- and post-treatment. Prototyping work on the balloon-stent device is currently underway.

Disclosures O. Asgari: 1; C; the 2021 Flinn Foundation Medical Technology Seed Grant. H. Berns: None. A. Arzani: None. T. Becker: None.

\section{0-007 LENGTH OF HOSPITAL STAY IN ANEURYSMAL SUBARACHNOID HEMORRHAGE PATIENTS WITHOUT VASOSPASM ON ANGIOGRAPHY: POTENTIAL FOR A FAST-TRACK DISCHARGE COHORT}

J Catapano*, V Srinivasan, K Rumalla, M Labib, C Ngueyen, T Cole, J Baranoski, C Rutledge, R Rahmani, M Lawton, A Ducruet, F Albuquerque. Neurosurgery, BNI, Phoenix, $A Z$

\subsection{6/neurintsurg-2021-SNIS.7}

Background Aneurysmal subarachnoid hemorrhage (aSAH) patients frequently suffer from vasospasm. We analyzed the association between absence of early angiographic vasospasm and early discharge.

Methods All treated aSAH patients (August 1, 2007-July $31,2019)$ at a single tertiary center were reviewed. Patients undergoing diagnostic digital subtraction angiography (DSA) on post-aSAH days 5 to 7 were included in the analysis; cohorts with and without angiographic vasospasm (angiographic reports by attending neurovascular surgeons) were compared. Primary outcome was hospital length of stay; secondary outcomes were ICU length of stay, 30-day return to the emergency department (ED) and poor neurologic outcome, defined as a modified Rankin Score (mRS) score $>2$.

Results A total of 298 patients underwent DSA on post-aSAH day 5, 6, or 7. Most patients $(n=188,63 \%)$ had angiographic vasospasm, whereas 110 patients $(37 \%)$ did not. The no-vasospasm cohort had a significantly lower mean length of hospital stay $(18.0 \pm 7.1$ days $)$ than the vasospasm group $(22.4 \pm 8.6$ days) $(\mathrm{p}<0.001)$. The 2 cohorts did not differ significantly in the percentage of patients with mRS scores $>2$ at last followup or those returning to the ED before 30 days. After adjustment for Hunt and Hess scores, Fisher grade, admission Glasgow Coma Scale score, and age, logistic regression analysis

Abstract 0-007 Table 1 Characteristics of patients with aSAH with and without angiographic vasospasm*

\begin{tabular}{|c|c|c|c|}
\hline Characteristic & $\begin{array}{c}\text { No Vasospasm } \\
(n=110)\end{array}$ & $\begin{array}{c}\text { Vasospasm } \\
(\mathrm{n}=188)\end{array}$ & P-value \\
\hline Age (yr) & $58.6(12.9)$ & $53.1(12.2)$ & $<0.001$ \\
\hline GCS on admission & $11.9(3.8)$ & $10.9(3.8)$ & 0.02 \\
\hline $\mathrm{mRS}$ at last follow-up & $2.5(2.0)$ & $3.1(2.0)$ & 0.01 \\
\hline Hunt and Hess grade & $2.8(1.1)$ & $3.1(1.1)$ & 0.01 \\
\hline Fisher grade & $3.7(0.7)$ & $3.7(0.6)$ & 0.36 \\
\hline Aneurysm size (mm) & $7.0(4.2)$ & $6.5(4.4)$ & 0.36 \\
\hline Total hospital stay (days) & $18.0(7.1)$ & $22.4(8.6)$ & $<0.001$ \\
\hline Last follow-up (days) & $835.4(1335.6)$ & $834.6(1319.0)$ & 0.99 \\
\hline Open surgical clipping, $n(\%)$ & $55(50)$ & $122(65)$ & 0.01 \\
\hline VPS, n (\%) & $26(24)$ & $51(27)$ & 0.58 \\
\hline DSA complication, $\mathrm{n}(\%)$ & $3(3)$ & $7(4)$ & 0.64 \\
\hline
\end{tabular}


Abstract 0-007 Table 2 Outcomes of patients with aSAH with and without angiographic vasospasm*

\begin{tabular}{|c|c|c|c|}
\hline Characteristic & $\begin{array}{c}\text { No Vasospasm } \\
(\mathbf{n}=110) \\
\mathbf{n}(\%)\end{array}$ & $\begin{array}{c}\text { Vasospasm } \\
(\mathbf{n}=188) \\
\text { n (\%) }\end{array}$ & P-value \\
\hline Hospital discharge $\leq$ post-aSAH day 14 & $37(34)$ & $22(12)$ & $<0.001$ \\
\hline mRS score $>2$ at last follow-up & $51(46)$ & $106(56)$ & 0.12 \\
\hline $\begin{array}{l}\text { mRS score }>2 \text { at last follow -up with at least } 6 \\
\text { months of follow-up }\end{array}$ & $12(26)$ & $21(27)$ & 0.86 \\
\hline Return to the ED within 30 days of discharge & $13(12)$ & $30(16)$ & 0.39 \\
\hline
\end{tabular}

*Angiographic vasospasm defined on the basis of digital subtraction angiography on post-aSAH day 5-7.

Abbreviations: aSAH, aneurysmal subarachnoid hemorrhage; ED, emergency department; mRS, modified Rankin Scale

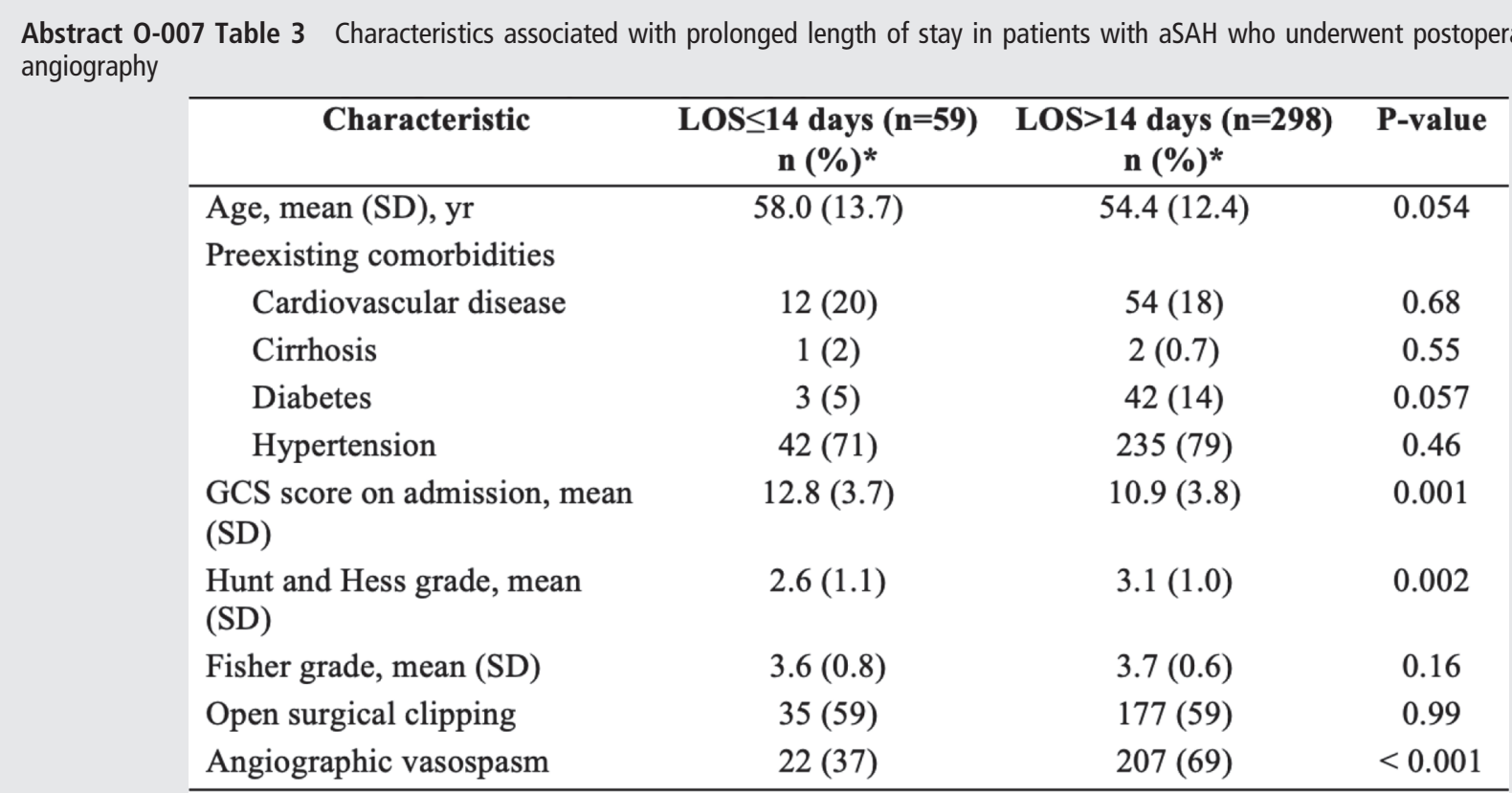

*Data are presented as number (percentage) unless otherwise indicated.

Abbreviations: aSAH, aneurysmal subarachnoid hemorrhage; GCS, Glasgow Coma Scale; LOS, length of stay

showed that absence of vasospasm on post-aSAH day 5-7 predicted discharge on or before hospital day 14 (OR 3.4, 95\% CI 1.8-6.4, p<0.001).

Conclusion Lack of angiographic vasospasm 5 to 7 days after aSAH is associated with shorter hospitalizations, with no increase in 30-day ED visits or poor neurologic outcome.

Disclosures J. Catapano: None. V. Srinivasan: None. K. Rumalla: None. M. Labib: None. C. Ngueyen: None. T. Cole: None. J. Baranoski: None. C. Rutledge: None. R. Rahmani: None. M. Lawton: None. A. Ducruet: None. F. Albuquerque: None.
O-008 ENDOVASCULAR EMBOLIZATION VS. SURGERY FOR
RUPTURED INTRACRANIAL ANEURYSMS: A
PROPENSITY-MATCHED STUDY OF 2,740 PATIENTS IN
THE TRINETX ANALYTICS NETWORK 